\title{
A Utilização da Gaseificação de Pneus Usados em Leito Fluidizado para a Produção de Energéticos
}

\author{
Eduardo A. Goulart, Carlos A. Mariotoni e Caio G. Sànchez
}

Resumo: O crescimento das grandes cidades, da industrialização e do consumo, tem orçado a civilização a conviver com um processo mais intenso de degradação do meio ambiente, ameaçando os recursos naturais e energéticos, além da maior produção de resíduos sólidos, líquidos e gasosos. Isto tem trazido preocupação com relação à sustentabilidade do processo de crescimento das economias mundiais e ao futuro dos recursos esgotáveis. Desta forma, torna-se essencial a utilização de combustíveis obtidos a partir de fontes renováveis ou dos resíduos gerados pela atividade industrial e pelas cidades. Alguns dos resíduos mais representativos do processo de crescimento dos centros urbanos são os pneus automotivos que descartados sem quaisquer cuidados trazem sérias consequências ao meio ambiente e às populações. Com este objetivo apresentamos a proposta de processamento desse resíduo através da gaseificação em um reator de leito fluidizado. Os sub-produtos deste processamento possuem elevado potencial de reutilização na indústria, quer seja como insumos de processos produtivos (negro de fumo presente nas cinzas), quer seja como energéticos (voláteis e o óleo obtido a partir da condensação dos vapores da gaseificação). Este último sub-produto apresenta boas qualidades como combustível (seu PCI é de cerca de $40 \mathrm{MJ} / \mathrm{kg}$ ). Este trabalho apresenta alguns dos resultados obtidos em tais experimentos.

Palavras-chave: Reciclagem energética, pneus automotivos, gaseificação, leito fluidizado, termoconversão.

\section{Introdução}

No Brasil são descartados atualmente cerca de 17 milhões de pneus por ano ${ }^{[1]}$, sendo que este número representa $7 \%$ do descarte americano e $70 \%$ do descarte da Grã-Bretanha. Os números da produção deste tipo de resíduo ao redor do mundo são extremamente preocupantes ${ }^{[2]}$ uma vez que existem poucos programas e iniciativas no sentido de sua eliminação ou redução. Por outro lado, sabe-se também do elevado potencial energético desses resíduos, cerca de $8500 \mathrm{kcal} / \mathrm{kg}^{3}$, incenti- vando seu aproveitamento como fonte alternativa de energia.

As formas mais comuns de disposição de pneus, em pilhas a céu aberto, em aterros ou em leitos de rios, têm apresentado sérios problemas ambientais. Uma das alternativas mais recomendadas para o processamento de pneus automotivos é sua termoconversão em leito fluidizado. Neste sentido tem sido empregadas: a combustão visando a obtenção de sólidos, a pirólise adequada à produção da fração líquida e a gaseificação para a otimização da fração gasosa. 
Este trabalho apresenta os resultados obtidos pela gaseificação de fragmentos de pneus usados em leito fluidizado, através de um reator, para a obtenção de um óleo com elevado poder calorífico inferior, cinzas com alto teor de negro de fumo e gases com significativo poder calorífico.

\section{Iniciativas visando a reciclagem de pneus automotivos}

Algumas iniciativas têm sido apresentadas nos últimos anos como forma de reaproveitamento ou eliminação deste resíduo. Porém ainda não foi relatado nenhum processo completamente isento de contra-indicações.

Segundo Matthee ${ }^{[4]}$, na Alemanha Oriental, onde anualmente são produzidas cerca de 350.000 toneladas de pneus descartados, criou-se a partir de 1978, a conscientização da necessidade do desenvolvimento de outros combustíveis alternativos àqueles empregados nos fornos de cimento alemães. Isto deu origem a um teste piloto da queima de pneus em fornos de cimento na planta de Amoneburg em Wiesbaden, registrando-se que após mais de três anos de operação não foram encontrados maiores problemas nesta unidade. O consumo de pneus desta planta só foi limitado pela disponibilidade de pneus automotivos descartados, uma vez que este processo compete com o mercado de pneus usados e com o mercado de reciclagem de borracha. O consumo energético por unidade de calor gerado até então observado foi reduzido de $50 \%$ com o uso de pneus em relação ao proporcionado pelo uso do lignito.

$\mathrm{Na}$ Grã-Bretanha ${ }^{[5]}$ tem-se o exemplo de um dos primeiros projetos de incinerador de pneus para a produção de energia elétrica (Wolverhampton - West Midlands) busca incinerar mais de 90.000 ton. de borracha por ano, para gerar cerca de $25 \mathrm{MW}$, ou seja, cerca de $280 \mathrm{~W} /$ ton., mais do que poderia ser obtido com peso equivalente de carvão. Como subprodutos podem ser obtidos cerca de 15.000 ton. de aço e 2.000 ton. de óxido de zinco. Apesar das críticas de grupos ambientalistas este incinerador apresenta três sistemas de despoluição ativos: um captura o óxido de zinco, outro remove cerca de $90 \%$ do ácido sulfúrico e o terceiro remove o material particulado.

Outra forma de reciclagem bastante empregada, especialmente nos EUA, é a adição da borracha dos pneus no asfalto ${ }^{[6]}$. Indústrias de plásticos como a Air Products and Chemicals, Inc. em Allentown, na Pensilvânia (EUA), tem combinado a borracha dos pneus com polímeros comerciais como os poliuretanos, epoxis e silicones, de forma a obter vários tipos de materiais.

\section{Caracterização do material}

Para qualquer forma de tratamento é de grande importância o prévio conhecimento da composição deste resíduo. Segundo Williams et al. ${ }^{[7]}$ os componentes presentes em maior quantidade na borracha dos pneus são a borracha estirenobutadieno (SBR), a borracha natural (NR) e a borracha polibutadieno (BR). Também aparecem: o negro de fumo, os óleos, o enxofre, o acelerador, o ácido esteárico e o óxido de zinco. $\mathrm{O}$ negro de fumo é usado para conferir à borracha resistência aos esforços e à abrasão, e os óleos são misturas de hidrocarbonetos aromáticos que servem para
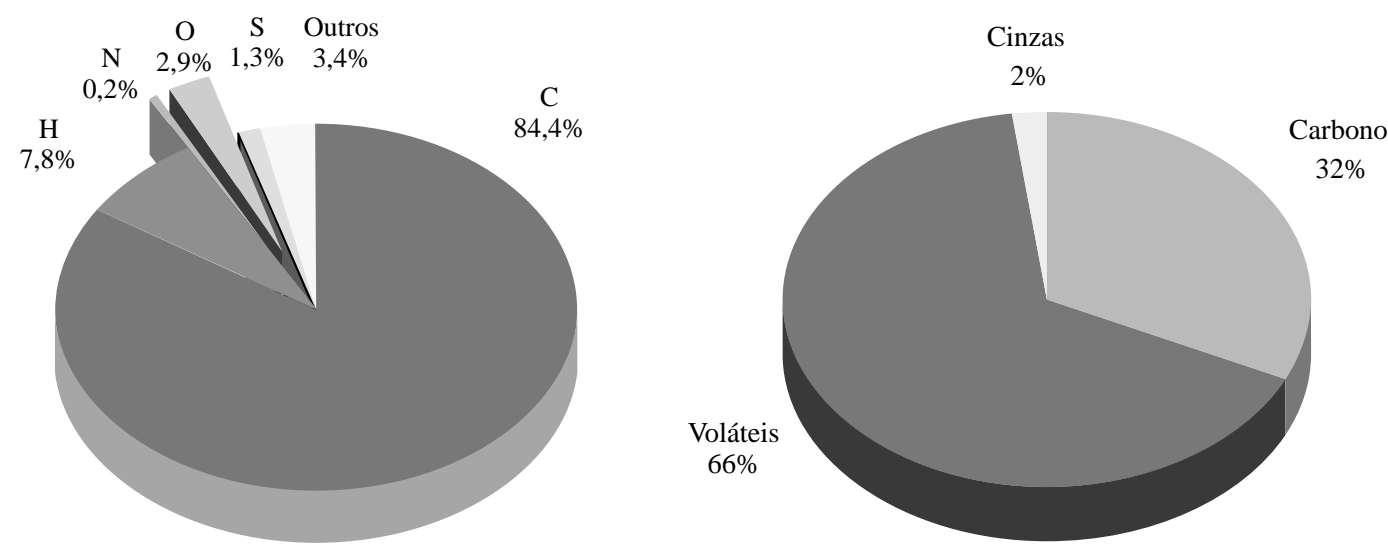

Figura 1. Análise elementar e imediata dos fragmentos empregados 
conferir maciez à borracha e aumentar sua trabalhabilidade durante a confecção dos pneus. O enxofre é usado para ligar as cadeias de polímeros dentro da borracha e também para endurecer e prevenir deformação excessiva pelas elevadas temperaturas. O acelerador é tipicamente um composto organo sulfúrico que age como um catalisador para o processo de vulcanização. O óxido de zinco e o ácido esteárico também agem para controlar a vulcanização e realçar as propriedades físicas da borracha. Os fragmentos de pneus utilizados possuem as características apresentadas na Figura 1.

\section{Processamento do material}

Os processos de combustão, pirólise e gaseificação de pneus automotivos tem sido pesquisados há várias décadas, tendo inclusive sido projetadas e construídas não apenas unidades em escala de laboratório mas também algumas unidades em escala comercial, visando principalmente o reaproveitamento de alguns dos sub-produtos desse processamento.

A pirólise é o processo de termoconversão realizado sob atmosfera isenta de oxigênio e proporcionado pela adição de calor a um material carbonáceo. Com a adição de oxigênio em excesso tem-se a combustão, onde deve ocorrer a oxidação total do material. Na combustão ocorre a liberação da energia correspondente às reações exotérmicas, o que acarreta o aumento da temperatura. Já a gaseificação é um processo intermediário, que consiste na inserção de oxigênio insuficiente para a combustão completa. Neste pro-

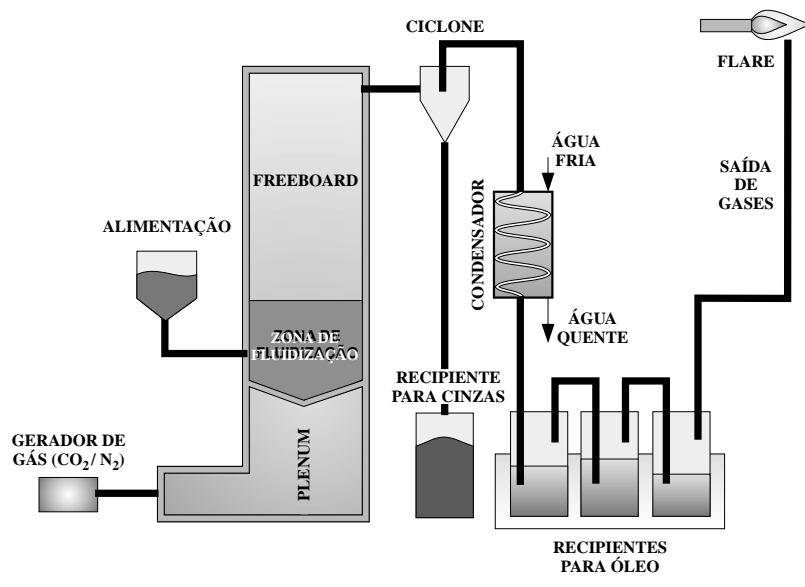

Figura 2. Diagrama esquemático do aparato a ser empregado cesso acabam ocorrendo, simultaneamente a pirólise e a combustão no interior do leito, sendo que as reações exotérmicas acabam por fornecer a energia necessária para a ocorrência das reações endotérmicas da pirólise.

Entre as técnicas mais empregadas para este processo de termoconversão temos a do leito fluidizado, que consiste na introdução de um fluxo gasoso na direção vertical e no sentido ascendente, atravessando um leito composto por material granulado inerte (geralmente areia ou alumina). O material a ser processado é incorporado a este leito, recebendo deste a energia necessária para a sua decomposição térmica.

A técnica de leito fluidizado proporciona grande movimentação interna na região de fluidização, o que acaba por homogeneizar a temperatura em seu interior e permitir o surgimento de pirólise, combustão e redução simultaneamente em vários pontos do leito o que melhora sensivelmente a qualidade dos produtos obtidos.

$\mathrm{O}$ aparato empregado apresenta a configuração mostrada na Figura 2. Foram executados 7 (sete) pré-ensaios objetivando o ajuste de todos os parâmetros operacionais do equipamento, entre os quais pode-se citar a fluidização a frio, a estabilização do queimador, a fluidização a quente, o ajuste da relação ar combustível de operação do pré-aquecedor, a alimentação de borracha a quente e, finalmente, a gaseificação dos fragmentos de pneus. Após os ajustes dos referidos parâmetros, foram efetuados 3 (três) ensaios variando-se o fator de ar.

$\mathrm{O}$ experimento realizado alimentou fragmentos de pneus a uma taxa média entre 7 e $8 \mathrm{~kg} / \mathrm{h}$, com fatores de ar variando entre 0,40 e 0,45 . O ensaio $01(\varphi=0,40)$ teve seus resultados prejudicados pela perda de uma parte do óleo formado o que prejudicou o balanço de energia do processo, já o ensaio 02, que repetiu o fator de ar 0,40, e o ensaio 03 que teve fator de ar de 0,45 , tiveram seus resultados válidos para efeito dos balanços de massa e energia.

\section{Sub-produtos e resíduos do processo}

A seguir serão apresentados alguns dos resultados dos experimentos realizados com a gaseificação dos fragmentos de pneus. Conforme já 

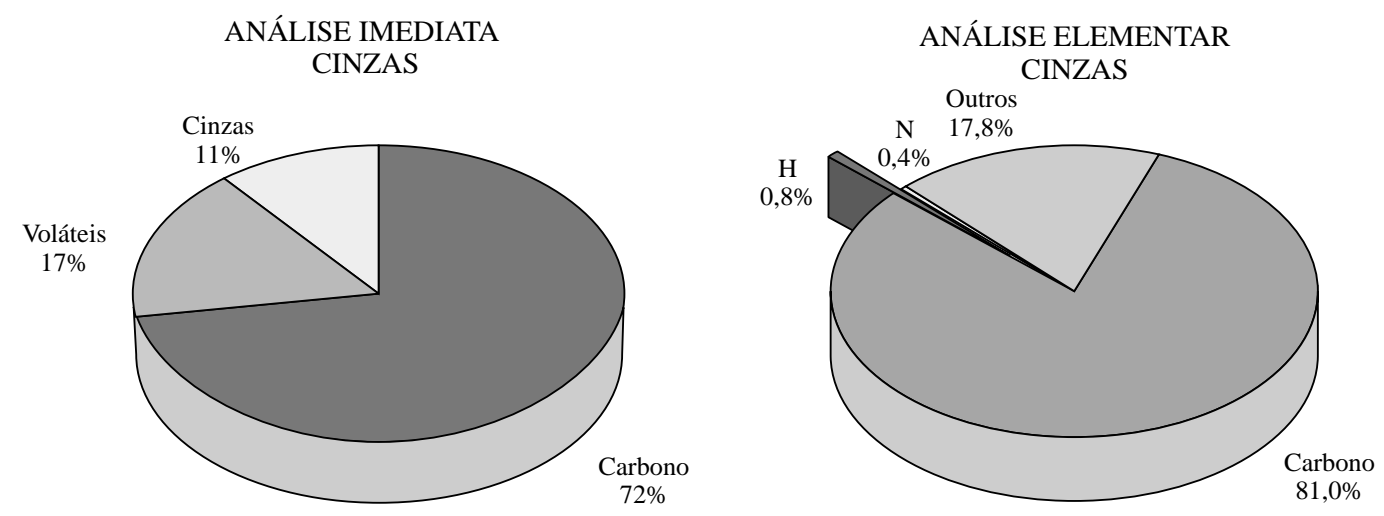

Figura 3. Características das cinzas obtidas

mencionado os sub-produtos deste processo são as cinzas (coletadas no separador ciclone), o óleo (coletado nos recipientes de óleo e no alimentador), e os gases (amostrados antes da queima no flare).

As cinzas formadas apresentaram as características mostradas na Figura 3. No nosso caso, as cinzas são compostas basicamente por negro de fumo acrescido de alguns outros compostos em menor quantidade $(94,6 \% \mathrm{C}, 2.8 \% \mathrm{O}, 0.7 \% \mathrm{~N}$, $1.2 \% \mathrm{~S}, 0.7 \% \mathrm{Zn})^{[8]}$. O negro de fumo da fração sólida, geralmente acrescido de algumas impurezas como o $\mathrm{ZnS}$, formado pela reação do óxido de zinco com o enxofre ambos contidos nos pneus.

As composições médias dos gases em cada um dos ensaios são apresentadas na figura 4. As variações podem ser explicadas pelas oscilações naturais do processo uma vez que ocorrem variações na vazão mássica de borracha e de consequentemente de temperatura ao longo do experimento. Cabe salientar que os percentuais apresentados, para cada um dos experimentos, nesta tabela tratam-se dos valores médios de todos os cromatogramas a ele referentes.

A forte presença do nitrogênio nos gases produzidos é explicada pela composição do ar utiliza- do pelo sistema onde a razão $\mathrm{N}_{2} / \mathrm{O}_{2}$ se situa em torno de 3:1. As frações de $\mathrm{CH}_{4}, \mathrm{CO}$ e $\mathrm{H}_{2}$ são as responsáveis pelo poder calorífico da mistura gasosa.

O Poder Calorífico do óleo obtido foi determinado por meio de uma bomba calorimétrica, segundo a norma ASTM D 2015-77. Como resultado obteve-se o PCS (Poder Calorífico Superior) de $42,62 \mathrm{MJ} / \mathrm{kg}$ e o PCI (Poder Calorífico Inferior) de $40,40 \mathrm{MJ} / \mathrm{kg}$. Este resultado é apresentado na Figura 5, que compara o Poder Calorífico Inferior de diversos combustíveis, comparativamente ao do óleo derivado dos pneus e comprova os dados de literatura. Como se observa na figura, o poder calorífico deste óleo é comparável ao de outros combustíveis comercialmente disponíveis.

A conversão de pneus em seus sub-produtos durante o ensaio 2 realizado é apresentada na Figura 6. A interpretação deste gráfico é que, para cada $100 \mathrm{~g}$ de fragmentos de pneus processados, obtém-se $20 \mathrm{~g}$ de cinzas e $7 \mathrm{~g}$ de óleo. O resultado do ensaio 03 foi inferior ao do ensaio anterior no tocante à produção de óleo (cerca de $5 \%$ em massa de fragmentos de pneus, contra $7 \%$ do ensaio 02) e também de cinzas (cerca de $17 \%$ em
COMPOSIÇÃO MÉDIA DOS GASES ENSAIO 01

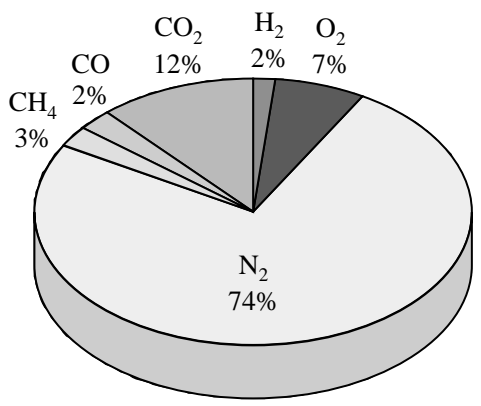

COMPOSIÇÃO MÉDIA DOS GASES ENSAIO 02

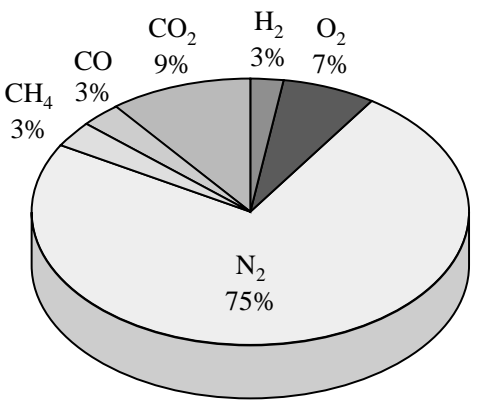

COMPOSIÇÃO MÉDIA DOS GASES ENSAIO 03

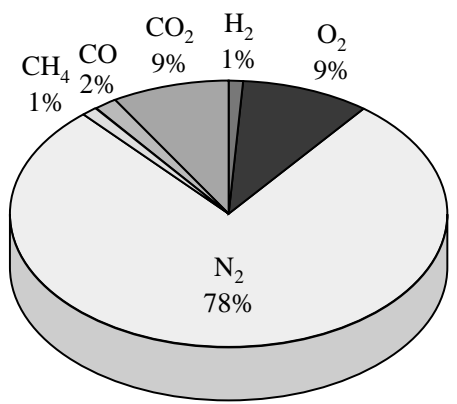

Figura 4. Composição média dos gases produzidos por ensaio 


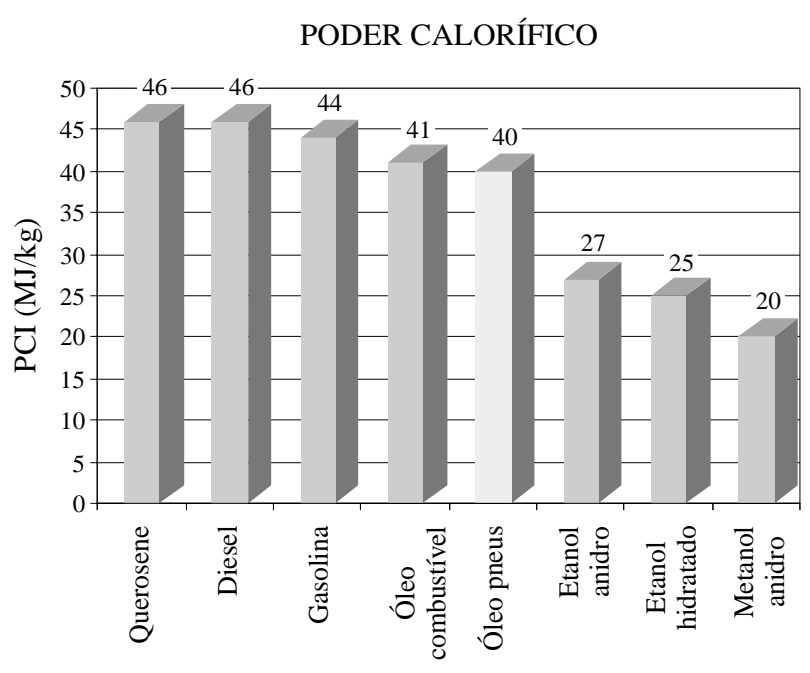

Figura 5. PCI do óleo obtido comparado a outros combustíveis

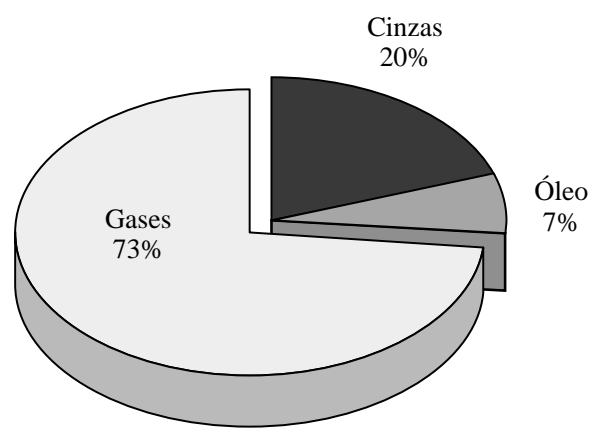

Figura 6. - Conversão média de borracha (em massa)

massa de fragmentos de pneus, contra $20 \%$ do ensaio 2).

$\mathrm{Na}$ fase líquida o óleo formado possui vários hidrocarbonetos como benzeno, dipenteno, estireno, indano, indeno, isopreno, octeno, tolueno e xileno. Ocorreu a formação de um óleo concentrado na região do sistema alimentador e, no sistema de coleta, o óleo formado se apresentou bastante diluído em água. Apesar de o grau de diluição deste condensado em água ter sido de cerca de 97\% (Figura 7), constatou-se grande similaridade na composição das frações de óleo produzidas nos dois pontos (Figura 8) após a extração da água da fração diluída.

Assim, os resultados obtidos pelo processo com o fator de ar $(\varphi) 0,40$ foram superiores aos obti$\operatorname{dos} \operatorname{com} \varphi=0,45$, acarretando sub-produtos com melhores propriedades e em quantidades mais significativas. Constatou-se também que, a eficiência do processo ainda pode ser melhorada através da investigação de outros fatores de ar, possivelmente inferiores aqueles empregados. Esta redução deve, provavelmente, privilegiar a formação

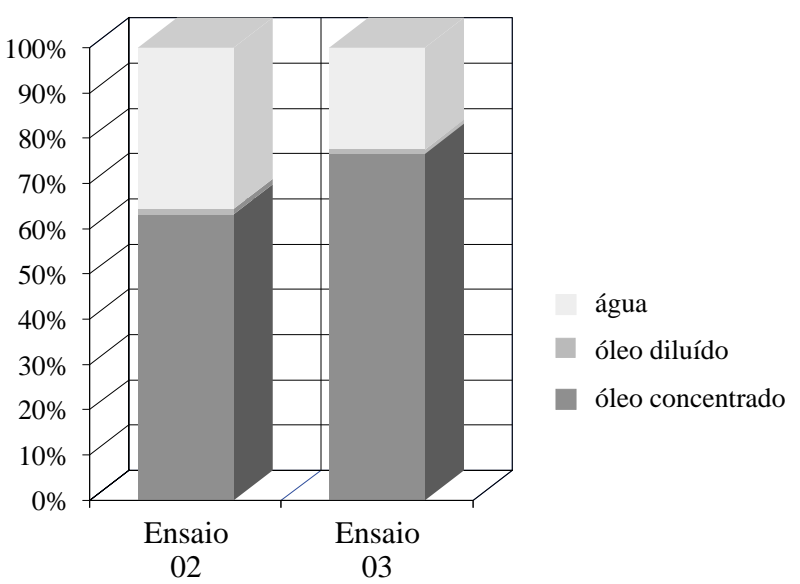

Figura 7. Frações de óleo coletadas

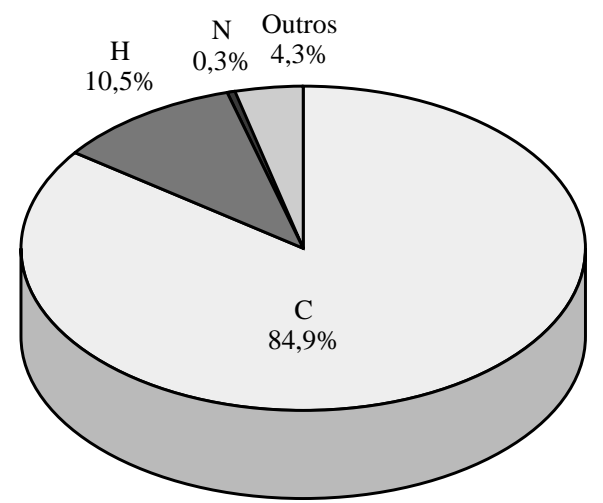

Figura 8. Análise elementar do óleo

da fração líquida em detrimento das demais frações, confirmando a tendência ao emprego da pirólise para a otimização da obtenção de óleo derivado de pneus.

Outro fator importante foi o fato de que houve uma redução de massa de pneus, no ensaio 02 , em torno de $73 \%$ (restando apenas as cinzas com $20 \%$ e o óleo com $7 \%$ ), o que credencia o processo como forma de redução volumétrica do resíduo sólido em referência.

Deve-se observar, no entanto que os gases e o óleo produzidos, possuem compostos carcinogênicos e mutagênicos em sua composição, representando, quando não tratados corretamente, risco ao meio ambiente, juntamente com o SOx, também produzido e responsável pela chuva ácida.

Como forma de evitar tais consequências foram necessários vários sistemas de tratamento de efluentes. Entre estes sistemas pode-se mencionar:

- Condensador e recipientes para coleta do óleo;

- Removedor Ciclônico de Sólidos, para a remoção do particulado (cinzas); 
- Lavador de gases responsável pela remoção do SOx e particulado remanescente;

- Flare na saída da chaminé, para a queima do $\mathrm{CO}$, dos voláteis;

\section{Conclusão}

A investigação dos parâmetros envolvidos na gaseificação de fragmentos de pneus, através de um reator de leito fluidizado, indicou que fatores de ar inferiores acabam por favorecer a formação da fração de óleo. Também percebeu-se a viabilidade do tratamento dos efluentes deste processo desde que garantidas a estanqueidade do sistema e a presença de equipamentos para o tratamento de gases, coleta de particulado e de óleo. Este óleo obtido, por outro lado, apresentou características energéticas adequadas para o emprego como combustível, embora ainda seja necessária a sua completa caracterização, além do estudo de impacto de sua aplicação com este fim, uma vez que possui componentes carcinogênicos e mutagênicos.

Entre as maiores críticas frequentemente vinculadas ao processo de termoconversão tem-se a liberação dos efluentes gasosos e a produção de cinzas. Nas queimas não controladas deste material sabe-se que ocorre grande emissão de hidrocarbonetos gasosos causadores do forte odor relacionado ao processo. Juntamente com estes voláteis temos o carreamento de parte das cinzas e da fuligem, que entre outras coisas é responsável pela coloração escura da fumaça liberada. Finalmente, no local da queima permanecem as cinzas e a fração líquida composta por hidrocarbonetos mais pesados, responsáveis pela contaminação do lençol freático. Por essa experiência que se tem do processo não controlado, ocorrem grandes resistências políticas, à solução da queima controlada dos pneus.

Processo mais barato e simples, a disposição em aterros não se apresenta como a solução definitiva uma vez que apenas armazena o resíduo por dezenas ou centenas de anos, e seu custo tem aumentado com a falta de áreas disponíveis e com a preocupação com a questão da saúde pública (proliferação de mosquitos transmissores de do- enças). Seu investimento inicial é baixo, mas proporciona um custo indireto cada vez maior, representado pelo custo da terra, o investimento com a saúde pública e com a prevenção de incêndios. Enquanto que no caso do processamento térmico o investimento inicial é muito maior, mas os custos indiretos são minimizados, isso sem contar a possibilidade de reaproveitamento de recursos através da re-inserção dos resíduos no processo de fabricação de pneus e de outros bens manufaturados.

\section{Referências Bibliográficas}

1. Goulart, E. A. - "Reciclagem Energética de Pneus Automotivos em Reator de Leito Fluidizado: Uma Proposta para a Questão Ambiental", dissertação de mestrado, 100 p. (1999).

2. Roy, C.; Unsworth, J.; In: Ferrero, G.L., Maniatis, K. et al. (Ed.) - Pyrolysis and Gasification. London: Elsevier Applied Science (1989).

3. Kim, J. R.; Lee, S. D. - Combustion characteristics of shredded waste tires in a fluidized bed combustor. Energy, Vol. 19, n ${ }^{\circ}$ 8, p. 845854 (1994).

4. Matthee, H. Experience in West Germany. In: ROBINSON, W.D. (Ed.). The Solid Waste Handbook: A Practical Guide.; John Wiley \& Sons, p.743-748 (1986).

5. Pearce, F. - Scrap Tires: a burning issue. New Scientist, November, p. 13-14 (1993).

6. Riggle, D. - New Uses for Old Tires. Biocycle, Vol. 33, no 4, p. 40-42 (1992).

7. Williams, P. T.; Besler, S. - Pyrolysis-thermogravimetric analysis of tires and tyre components. Fuel, Vol. 74, no 9, p. 1277-1283 (1995).

8. Darmstadt, H.; Roy, C.; Kaliaguine, S. - Esca Characterization of Commercial CarbonBlacks and of Carbon-Blacks form Vacuum Pyrolysis of Used Tires. CARBON. Vol. 32, $n^{\circ} 8$, p. 1399-1406 (1995). 